\title{
Clinical Features of Patients with Probable 2019 Novel Coronavirus Infected Pneumonia in Rasht, Iran: A Retrospective Case Series
}

\author{
Samad Karkhah ${ }^{1}$, Mohammad Javad Ghazanfari ${ }^{2}$, Amir Shamshirian ${ }^{3,4}$, Latif Panahi ${ }^{1}$, Meysam Molai ${ }^{5}$, Amir Emami Zeydi ${ }^{6 *}$ \\ ${ }^{1}$ Student Research Committee, School of Nursing and Midwifery, Guilan University of Medical Sciences, Rasht, Iran; ${ }^{2}$ Student \\ Research Committee, School of Nursing and Midwifery, Kashan University of Medical Sciences, Kashan, Iran; ${ }^{3}$ Department \\ of Medical Laboratory Sciences, Student Research Committee, School of Allied Medical Sciences, Mazandaran University of \\ Medical Sciences, Sari, Iran; ${ }^{4}$ Gastrointestinal Cancer Research Center, Mazandaran University of Medical Sciences, Sari, \\ Iran; ${ }^{5}$ Student Research Committee, School of Medicine, Guilan University of Medical Sciences, Rasht, Iran; ${ }^{6}$ Department of \\ Medical-Surgical Nursing, Nasibeh School of Nursing and Midwifery, Mazandaran University of Medical Sciences, Sari, Iran
}

\section{Abstract}

Edited by: Mirko Spiroski Citation: Karkhah S, Ghazanfari MJ, Shamshirian A Panahi L, Molai M, Emami Zeydi A. Clinical Features of Patients with Probable 2019 Novel Coronavirus Infected Pneumonia in Rasht, Iran: A Retrospective Case Series. Open-Access Maced JMed Sci. 2020 May 10; 8(T1):16-22. Keywords: COVID19; Iran; COVID-19 diagnostic testing; *Correspondence: Dr. Amir Emami Zeydi, Department of Medical-Surgical Nursing, Nasibeh School of Nursing and Midwifery, Mazandaran University of Medical Sciences,
Sari, Iran. Tel.. + 981133367343 . E-mail: emamizeydi@ Sari, Iran. Tel.: +981133367343. E-mall. emamizeydi@ Received: 08-Apr-2020 Revised: 19-Apr-2020 Copyright: $\odot 2020$ Samad Karkhah, Mohammad Javad Ghazanfari, Amir Shamshirian, Latif Panahi, Meysam Molai, Amir Emami Zeydi
Funding: Publication of this article was financially Funding: Publication of this article was financially
supported by the Scientific Foundation SPIROSKI, Skopje, Republic of Macedonia Competing Interests: The authors have declared that no
competing interests exist Competing Interests: The authors have declared that no
competing interests exis Open Access: This is an open-access article distributed
under the terms of the Creative Commons Attributionunder the terms of the Creative Commons Attribution-
NonCommercial 4.0 International License (CC BY-NC 4.0)

BACKGROUND: Coronavirus disease-19 (COVID-19) is the first pandemic infectious disease caused by a nove coronavirus. Viral pneumonia is a severe complication of COVID-19.

AIM: Due to the high prevalence of this disease globally, especially in Iran, the aim of this study was to determine the clinical features of seven patients with probable COVID-19 infected pneumonia in Rasht, North Iran.

MATERIALS AND METHODS: In this retrospective case series study, we described the clinical, laboratory, and radiological features of seven patients with probable COVID-19 infected pneumonia at Razi Hospital, Rasht, north of Iran, from February 27 to March 16, 2020

RESULTS: In this study, the most common clinical symptoms during hospitalization in patients with COVID-19 were poor appetite (seven cases), dehydration (seven cases), cough (six cases), dyspnea (six cases), fatigue (six cases), fever above $38^{\circ} \mathrm{C}$ (five cases), myalgia (five cases), Chills (five cases), feeling fever (five cases), sore throat (five cases), and nausea (five cases), respectively. The average body temperature in these patients was $39.32^{\circ} \mathrm{C}$. In laboratory findings, erythrocyte sedimentation rate was elevated in three patients. Contrary to most of the evidence, $\mathrm{C}$-reactive protein was not elevated in five patients. All patients received antibiotic and antiviral medications and received symptomatic treatment. Finally, four patients responded to the treatments and were discharged from the hospital; two patients were still hospitalized and only one patient died

CONCLUSION: Patients with COVID-19 associated pneumonia can be treated by evaluating and implementing appropriate therapeutic management. However, at the moment the disease progression for patients with COVID-19 cannot be accurately predicted.

\section{Introduction}

Concerns have been raised about a new outbreak in the world since December 8, 2019, in Wuhan, Hubei Province, China, following reports of pneumonia with unknown etiology. These patients mostly lived or worked in the wholesale markets of Huawei seafood (the buying and selling of live animals) [1], [2]. Following the identification of the new coronavirus by the Chinese Centers for Disease Control and Prevention (China CDC), the disease has named Coronavirus Disease 2019 by the World Health Organization (WHO) [3], [4], [5]. Since January 2020, the spread of the disease has increased first in China and then in other countries [3] and by February 10, 2020, a total of 40,261 cases have been diagnosed in China, with 909 deaths [1], [6]. The disease is transmitted from person to person [4] and according to the latest WHO report, COVID-19 affected up to 179,111 individuals globally by March 17, 2020, of which 7426 people have died [7].
The Iranian Ministry of Health and Medical Education also reported 14,991 cases of COVID-19 in Iran by March 17, 2020, of which 853 cases have died [8].

According to the previous studies, symptoms such as fever, cough, myalgia, fatigue, diarrhea, shortness of breath, lymphopenia, and lung parenchymal opacity were detected in COVID-19 patients [9], [10]. The disease was associated with serious complications including acute respiratory distress syndrome (ARDS), shock, acute cardiac, and kidney injury and consequently, death. Clinically, patients with COVID19 develop rapidly and eventually severe respiratory failure [1]. Epidemiological studies indicated that the overall risk of mortality in affected critically ill patients is high. Older age, male sex, history of immunodeficiency disorders, smoking, and underlying diseases are major risk factors for developing severe symptoms of COVID19 [11], [12]. However, we have little information on clinical features in patients with OVID-19 infected pneumonia. 
Due to the high prevalence of COVID-19 and lack of sufficient details regarding underlying mechanism of disease, and its clinical presentation or treatment in these patients, the aim of this study was to determine the clinical features of seven cases with probable COVID-19 infected pneumonia to take a step to discover the unknowns of the disease caused by SARS-CoV-2.

\section{Case Presentation}

This study aimed to determine the clinical features of patients with COVID-19 infected pneumonia since February 27 to March 16, 2020, on seven cases referred to Razi Hospital in Rasht, Guilan Province, Iran. This hospital is the main center for the treatment of COVID-19 patients in Rasht. In this study, patients with suspected diagnosis of COVID-19 infected pneumonia were examined through clinical and radiological findings. Due to restricted access to reverse transcription polymerase chain reaction (RT-PCR) laboratory kits, in this study, the diagnosis of COVID-19 pneumonia was based on the results of chest computed tomography (CT) scan imaging findings, according to the criteria developed by Iranian Radiologic Consultant Group [13].

We extracted information from patient records and interviews using pre-designed researcher-made checklist. This checklist includes demographic and clinical characteristics including age, sex, occupation, residency location, underlying disease history, history of immunosuppressive illness, history of contact to COVID-19 patient, history of travel to the China, disease symptoms, radiological findings, and factors associated with the disease. Consent form was filled out by all of the patients, or their family member, anonymously to use their medical records, and treatment plan.

In this case series, seven patients with COVID19 pneumonia referred to the Razi Hospital in Rasht, Iran, were studied since February 27, 2010, to March 16, 2020. After early diagnosis, treatment and follow-up were performed for them. To protect patients' privacy, only purpose-related data were reported. There was no material or spiritual burden on the patients and their companions.

\section{Case 1}

The patient was a 79-year-old housewife. She was complaining about cough, loss of appetite and fatigue, which led her to the hospital. She had a history of hypertension and cardiovascular disease. She was under treatment with metoprolol and losartan. She did not have a history of travel or contact with a confirmed COVID-19 patient. The vital signs of the patient were $\mathrm{BP}=160 / 90, \mathrm{~T}=37.3, \mathrm{SPO}_{2}=84 \%, \mathrm{HR}=90$, and $\mathrm{RR}=18$. Oxygen therapy was performed immediately with mask (8L/min). Chest x-ray (CXR) and CT scan findings have showed bilateral pneumonia. Laboratory findings showed that patient alkaline phosphatase (336 U/L) were in high range. The patient treatments were symptomatic and included with antibiotic drugs, such as levofloxacin (750 mg, daily) and meropenem ( $1 \mathrm{~g}, 3$ times a day), as well as antiviral drugs, such as oseltamivir (75 mg, Twice daily) and hydroxychloroquine (200 mg, twice daily). The patient was discharged from the hospital after 11 days with complete recovery (Figure 1).

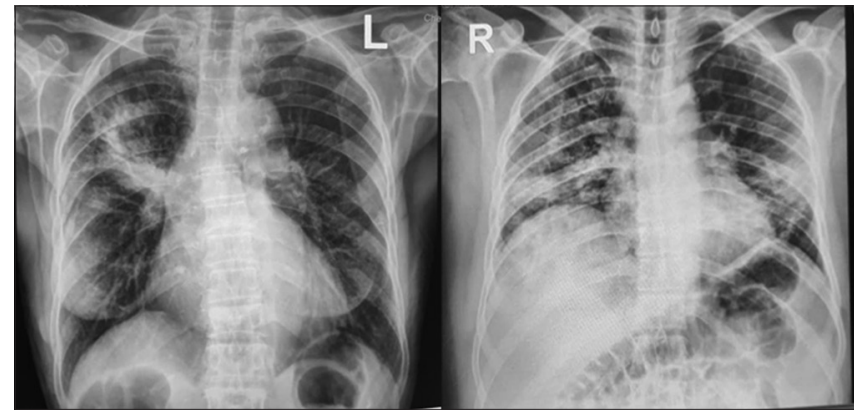

Figure 1: Chest $X$-Ray imaging from Patient 1 (Left) and Patient four (Right)

\section{Case 2}

The patient was a 51-year-old housewife who was referred to the hospital with her daughter with complaint of dry cough and shortness of breath, sore throat, and periodic fever $\left(39.5^{\circ} \mathrm{C}\right)$ and chills. On further examination, the patient also reported symptoms, such as chest pain, headache, and diarrhea. The patient did not mention any previous history of the disease. She had attended a ceremony about 2 weeks ago and had contact with a person whose COVID-19 RT-PCR test was positive. The patient symptoms were treated by antibiotic therapy and the antiviral drugs, such as oseltamivir (75 mg, twice daily) and hydroxychloroquine $(200 \mathrm{mg}$, twice daily). On the physical examination, the patient was observed with dehydration, myalgia, and fever. The vital signs of the patient were $B P=135 / 80, T=39.5$, $\mathrm{SPO}_{2}=86 \%, \mathrm{HR}=83$, and $\mathrm{RR}=16$. Oxygen therapy was performed immediately with mask (8 L/min). CXR and CT-scan findings indicated bilateral pneumonia. The patient was discharged after 12 days of care.

\section{Case 3}

The patient was a 68-year-old female, with symptoms of fever $\left(39.4^{\circ} \mathrm{C}\right)$, cough, sore throat, and shortness of breath, who had been hospitalized for several days, and had been referred to Razi Hospital through a pre-hospital emergency medical service. In the initial examination, the patient had temporary symptoms of anorexia, nausea, dehydration, and chest pain. She had no previous history of the disease. She did not have a history of travel to China or contact with a positive COVID-19 patient. The patient participated in school ceremony for 14 days before admission and hospitalization. The patient treatments were symptomatic and included with antibiotics, such as levofloxacin 
(750 mg, daily) and meropenem (1 g, 3 times a day), as well as antiviral drugs, such as oseltamivir ( $75 \mathrm{mg}$, twice daily) and hydroxychloroquine (200 mg, twice daily). The vital signs of the patient were $B P=100 / 60, T=37.2$, $\mathrm{SPO}_{2}=75 \%, \mathrm{HR}=88$, and $\mathrm{RR}=18$. Oxygen therapy was performed immediately with mask (8 L/min) to improve the patient's condition. CXR and chest CT-scan imaging findings have indicated a unilateral pneumonia. Laboratory findings showed the high levels of erythrocyte sedimentation rate (ESR) and negative $\mathrm{C}$-reactive protein (CRP). In laboratory tests, the patient had leukocytosis and hypernatremia. She was discharged after 14 days of care and improvement of clinical symptoms.

\section{Case 4}

The patient was a 40 years old, a teacher, who was referred to the emergency department with complaints of cough, sore throat, shortness of breath, nausea, vomiting, and diarrhea. On initial examination, the patient had symptoms of fatigue, anorexia, fever $\left(39^{\circ} \mathrm{C}\right)$, chills, and dehydration. There was no previous underlying disease. Due to exacerbation of condition and $\mathrm{SPO}_{2}=29.9 \%$, the patient was transferred to the intensive care unit (ICU) and subjected to intubation and underwent mechanical ventilation with synchronized intermittent mandatory ventilation mode. The patient has had a history of attending school for the past 14 days. The patient's treatment was symptomatic, using antibiotic and antiviral drugs. CXR and chest CT-scan results indicated a bilateral pneumonia. In the study of the patient's laboratory findings, creatine phosphokinase, creatine phosphokinase-MB, and ESR showed an increase of 271,103 , and 64 , respectively. The patient died after 4 days of intubation in the ICU due to severe pulmonary involvement and respiratory distress syndrome (Figure 1).

\section{Case 5}

The patient was a 65-year-old, retired, who was referred to emergency department of the hospital with complaints of shortness of breath, fatigue, and abdominal pain. In the skin turgor examination, patient had dehydration. The patient had no fever $(T=37.5)$, but gastrointestinal symptoms such as anorexia, nausea, vomiting, and diarrhea were observed for 3 days. The patient has not been in any meeting for the past 14 days. He had a history of diabetes and hypertension. Initially, the patient received oxygen $(6 \mathrm{~L} / \mathrm{min})$, levofloxacin (750 mg, daily), as well as oseltamivir (75 mg, twice daily), and hydroxychloroquine (200 mg, twice daily). CXR and chest CT-scan imaging results showed a unilateral pneumonia. Laboratory results were as follows: $\mathrm{LDH}=952$ (elevated), creatine phosphokinase $=54$ (elevated), and BS $=438$. After 11 days of symptomatic care, antibiotics and antiviral therapy, the patient was discharged with improved clinical symptoms.

\section{Case 6}

The patient was 58-year-old man who has been referred to emergency department by ambulance. The patient's chief complaints were high fever $\left(39.5^{\circ} \mathrm{C}\right)$, chills, dry cough, sore throat, and shortness of breath. On initial examination, the patient was suffering from chest pain, fatigue, and loss of appetite. He had been smoking a pack of cigarettes daily for the past 20 years. He had no history of underlying disease. He did not have a history of travel to China or contact with a positive COVID-19 patient. Initially, oxygen therapy (9 L/min) was performed for symptomatic treatment, but on the $2^{\text {nd }}$ day of hospitalization after reduction in arterial blood oxygen level $\left(\mathrm{O}_{2}\right.$ sat $\left.=72 \%\right)$, the patient was intubated and treated with bi-level positive airway pressure (BiPAP). Antibiotic therapy with levofloxacin $(750 \mathrm{mg}$, daily), as well as antiviral therapy with oseltamivir (75 mg, twice daily) and hydroxychloroquine (200 mg, twice daily) were administered to the patient. CXR and chest CT-scan results were also evaluated and bilateral pneumonia was observed. In the last follow-up after 19 days, he was hospitalized and received treatment.

\section{Case 7}

The patient was a 65-year-old man, who was presented to the hospital complaining of cough, sore throat, fever, chills, and night sweats. On further examination, the patient's appetite has decreased and he was suffering from fatigue, headache, and dehydration. The patient's initial temperature was $38^{\circ} \mathrm{C}$, which peaked at $39.2^{\circ} \mathrm{C}$ after 4 days. From day 5 , a decreasing trend was found and finally reached at $37.8^{\circ} \mathrm{C}$ on day 10 . The patient had a history of diabetes. On the other hand, he had traveled to Tehran in the past 14 days. The patient receives antibiotic and antiviral treatments with levofloxacin $(750 \mathrm{mg}$, daily) and oseltamivir (75 mg, twice daily). CXR and chest CT-scan imaging results were also reviewed and bilateral pneumonia was observed. The patient's LDH level was high (821 U/L). The patient is currently in hospital and undergoing treatment (Figure 2).

\section{Additional results}

The mean age of the patients was 60.85 years ranged from 40 to 79 years old. Four of the patients were male and three were female. All patients were residents of Rasht and were indirectly exposed and affected due to the widespread prevalence of this disease in this city. None of the patients had a close relationship with the history of traveling to China or with people who had traveled there. The patients' symptoms included: Poor appetite (seven cases), dehydration (seven cases), cough (six cases), dyspnea (six cases), fatigue (six cases), fever (five cases), myalgia (five cases), chills (five cases), feeling febrile (five cases), sore throat (five cases), nausea (five cases), vomiting 


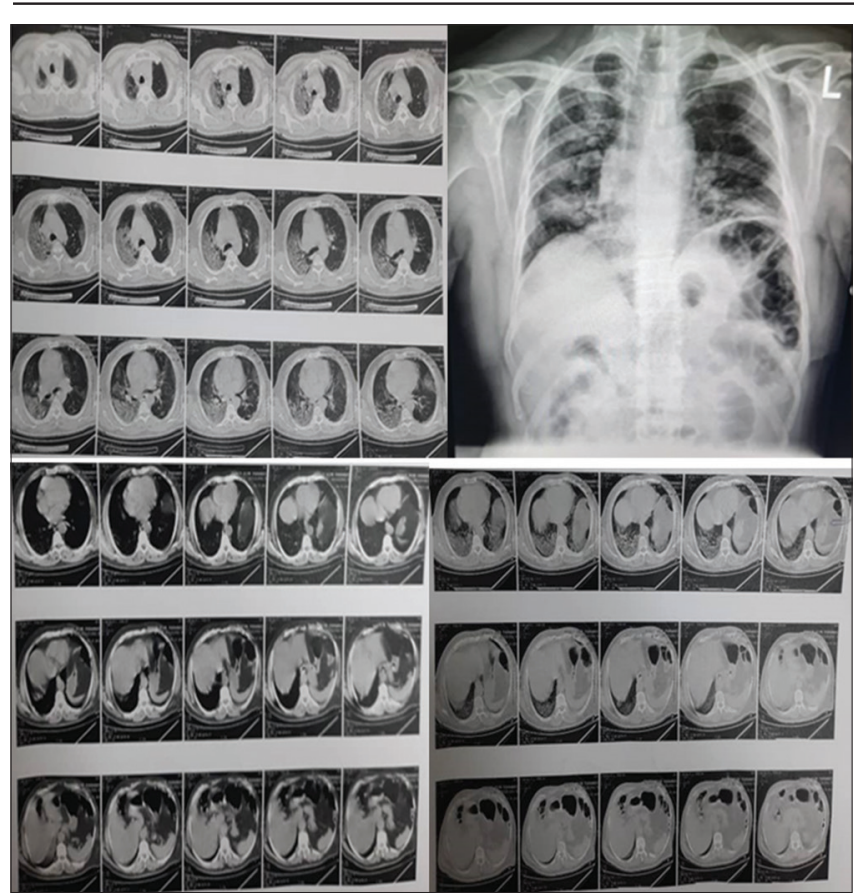

Figure 2: Transversal chest CT-scan and Chest $X$-Ray imaging from Patient seven

(four cases), headache (three cases), chest pain (three cases), diarrhea (three cases), and wheezing (one case). Body temperature higher than $38^{\circ} \mathrm{C}$ was observed in five patients with a mean of $39.32^{\circ} \mathrm{C}$ (from $39^{\circ} \mathrm{C}$ to $39.5^{\circ} \mathrm{C}$ ). The results of chest radiography revealed four cases with bilateral pneumonia, two cases of unilateral pneumonia with right lung involvement, and one case of unilateral pneumonia with left lung involvement. Furthermore, unilateral multiple mottling and ground glass opacity were observed in three cases. All patients received antibiotics and received symptomatic treatment, and three were intubated due to low $\mathrm{O}_{2}$ saturation. For all patients, medications such as: Oseltamivir capsule (75 mg, twice daily), hydroxychloroquine tablets (200 mg, twice daily), diphenhydramine $(10 \mathrm{ml}$, four times a day before meals), intravenous ranitidine (25 mg/ml, twice daily), acetaminophen tablets in case of pain, ondansetron tablets in case of nausea, salbutamol, and ipratropium spray (two puffs in case of shortness of breath; 4 times a day), ceftriaxone (1 g, twice daily), meropenem (1 g, twice daily), vancomycin ( $1 \mathrm{~g}$, twice daily), and oxygen therapy (in case of shortness of breath). A total of four patients responded appropriately to treatments and were discharged, two patients were still hospitalized and one patient expired. More detailed information is shown in Table 1. Furthermore, the patients' all laboratory data are presented in Table 2.

\section{Discussion}

Coronavirus is one of the major pathogens causing respiratory infections in humans. Two types of this pathogen including SARS-CoV and MERS-CoV are highly pathogenic, causing severe respiratory syndrome in humans [1]. Initial and major outbreaks of SARS-CoV between 2002 and 2003 leads to a total of 8422 confirmed infected cases in 29 countries [14]. MERS-CoV appeared in 2012 in Asia and the Middle East [15]. The SARS-CoV mortality rate was more than $10 \%$ and MERS-CoV was more than 35\% [16].

This study was conducted in Rasht, the capital city of Guilan Province, north of Iran, due to the high prevalence of the disease and the establishment of an epidemic area. None of patients in this study had a history of traveling to China, or contacts with people who came from China in the past 2 weeks. It seems that these patients had contact with suspected COVID19 patients, which was similar to Li et al. [3], but in the study of Chen et al., all patients were from individuals associated with the Chinese seafood market [1], which may be attributed to the study's location.

The most common clinical manifestations of patients with COVID 19 infected pneumonia in this study were poor appetite and dehydration (all patients), cough, sore throat, dyspnea, fatigue, fever higher than $38^{\circ} \mathrm{C}$, chills, and myalgia, respectively. However, a study by Chen et al. reported that fever, cough, and dyspnea were the most common symptoms in these patients [1]. Ethnicity and having underlying disease are the possible reasons for this difference. In a similar study, Wei Xu et al., in Wuhan, China, reported that the most common clinical symptoms of the patients were fatigue, myalgia, headache, diarrhea, and vertigo, respectively [3], [17]. According to the results of our study, about half of patients had underlying diseases, such as hypertension, diabetes mellitus, and cardiovascular disease. Badawi et al. reported that about half of MERS-CoV patients had underlying diseases, such as diabetes mellitus, hypertension, and heart disease [18]. Furthermore, in this study, similar to other studies, the majority of patients had older age, people with underlying diseases and reduced immune systems were more likely to be affected [1], [19].

According to the results of our study, unlike the study by Chen et al., the levels of lymphocytes and white blood cells were within the normal range [1]. Moreover, in our investigation, CRP were negative in most cases $(71.42 \%)$, which was consistent with the study by Wang et al. study [20]. It has been previously reported a $75-93 \%$ of elevated levels of CRP in COVID19 patients [1], [13], [21], [22], [23]. This might be related to underlying diseases and other characteristics of infected patients. There has been shown an inverse association between the underlying diseases such as diabetes mellitus, hypertension and kidney and liver disease and higher CRP level in patients with acute or chronic illnesses [2], [24], [25]. In our study, the serum levels of other biomarkers such as LDH and ESR were increased significantly in COVID 19 patients, that is in line with study of Chen et al. (85\% increase in ESR) [1]. The previous studies showed the increases 
Table 1: Clinical features among COVID-19 infected in Rasht, Iran

\begin{tabular}{|c|c|c|c|c|c|c|c|}
\hline & Patient 1 & Patient 2 & Patient 3 & Patient 4 & Patient 5 & Patient 6 & Patient 7 \\
\hline \multicolumn{8}{|l|}{ Basic information } \\
\hline Admission date (2020) & March 5 & March 6 & March 6 & February 28 & March 5 & February 27 & March 2 \\
\hline Age (years) & 79 & 51 & 68 & 40 & 65 & 58 & 65 \\
\hline Sex & Female & Female & Female & Male & Male & Male & Male \\
\hline Occupation & Housewife & Housewife & Housewife & Teacher & Retired & farmer & Freelance \\
\hline \multicolumn{8}{|l|}{ Epidemiological history } \\
\hline Contact with index case directly & Unknown & Yes & Unknown & Unknown & Unknown & Unknown & Unknown \\
\hline Current smoking & No & No & No & No & No & Yes & No \\
\hline Hypertension & Yes & No & No & No & Yes & No & No \\
\hline Diabetes & No & No & No & No & Yes & No & Yes \\
\hline Cardiovascular disease & Yes & No & No & No & No & No & No \\
\hline Coronary artery disease & Yes & No & No & No & No & No & No \\
\hline \multicolumn{8}{|l|}{ Clinical characteristics } \\
\hline Peak of fever $\left({ }^{\circ} \mathrm{C}\right)$ & Afebrile & 39.5 & 39.4 & 39 & afebrile & 39.5 & 39.2 \\
\hline Duration of fever (days) & -- & 7 & 2 & 6 & -- & 2 & 3 \\
\hline Cough & Yes & Yes & Yes & Yes & No & Yes & Yes \\
\hline Sore throat & No & Yes & Yes & Yes & No & Yes & Yes \\
\hline Dyspnea & No & Yes & Yes & Yes & Yes & Yes & Yes \\
\hline wheezing & No & No & No & No & Yes & No & No \\
\hline Diarrhea & No & Yes & No & Yes & Yes & No & No \\
\hline Nausea & No & Yes & Yes & Yes & Yes & Yes & No \\
\hline Vomit & No & No & No & Yes & Yes & Yes & Yes \\
\hline Abdominal pain & No & No & No & No & Yes & No & Yes \\
\hline Poor appetite & Yes & Yes & Yes & Yes & Yes & Yes & Yes \\
\hline Fatigue & Yes & No & Yes & Yes & Yes & Yes & Yes \\
\hline Dehydration & Yes & Yes & Yes & Yes & Yes & Yes & Yes \\
\hline Myalgia & No & Yes & Yes & Yes & No & Yes & Yes \\
\hline Feeling fever & No & Yes & Yes & Yes & No & Yes & Yes \\
\hline Chills & No & Yes & Yes & Yes & No & Yes & Yes \\
\hline Headache & No & Yes & No & No & No & Yes & Yes \\
\hline Chest pain & No & Yes & No & No & No & Yes & Yes \\
\hline \multicolumn{8}{|l|}{ Treatment } \\
\hline Symptomatic treatment & Yes & Yes & Yes & Yes & Yes & Yes & Yes \\
\hline Antibiotic & Yes & Yes & Yes & Yes & Yes & Yes & Yes \\
\hline Antivirus & Yes & Yes & Yes & Yes & Yes & Yes & Yes \\
\hline Oxygen therapy & No & Yes & Yes & Yes & Yes & Yes & Yes \\
\hline Intubation & No & No & No & Yes & No & Yes & Yes \\
\hline \multicolumn{8}{|l|}{ Chest X-ray and CT-scan findings } \\
\hline Bilateral or unilateral pneumonia & Unilateral right lung & Bilateral & Unilateral left lung & Bilateral & Unilateral right lung & Bilateral & Bilateral \\
\hline Multiple mottling and GGO & No & No & No & Yes & No & Yes & Yes \\
\hline Affected lobe & 2 & 3 & 2 & 5 & 2 & 4 & 4 \\
\hline Clinical outcome & Discharged & Discharged & Discharged & Died & Discharged & Remained in hospital & Remained in hospital \\
\hline
\end{tabular}

Table 2: Laboratory values of all patients

\begin{tabular}{|c|c|c|c|c|c|c|c|}
\hline & & & & & & & \\
\hline White blood cell count ( $\times 10 \square / L)$; (normal range $4-11$ ) & 8.7 & $3.3 \downarrow$ & $12.7 \uparrow$ & 6 & 7.1 & 7.7 & 6.9 \\
\hline Red blood cell count & 3.13 & 3.76 & 4.4 & 4.15 & 4.89 & 5.53 & 4.77 \\
\hline Hemoglobin $(\mathrm{g} / \mathrm{dL})$ & 9.1 & 10.7 & 11.3 & 11.9 & 14.9 & 14.7 & 13.8 \\
\hline Hematocrit $(\%)$ & 29 & 31.7 & 36.9 & 35.3 & 43.2 & 44.6 & 44.6 \\
\hline Mean corpuscular volume (F.L) & 92.7 & 84.3 & 83.9 & 85.1 & 88.3 & 80.7 & 93.5 \\
\hline Neutrophil count $(\%)$ & NA & NA & NA & NA & 70 & NA & NA \\
\hline Lymphocyte count (\%) & NA & NA & NA & NA & 27 & NA & NA \\
\hline Platelet count $(\times 10 \square / L)$ & 330 & 249 & 362 & 236 & 247 & 258 & 203 \\
\hline Erythrocyte sedimentation rate $1 \mathrm{~h}(\mathrm{~mm} / \mathrm{h})$ & NA & $114 \uparrow$ & $92 \uparrow$ & $64 \uparrow$ & NA & NA & NA \\
\hline Blood Sugar (mg/dL) & $141 \uparrow$ & 186 & NA & 109 & 438 & 162 & 349 \\
\hline BUN (mg/dL) & $28 \uparrow$ & 10 & $21 \uparrow$ & 20 & $36 \uparrow$ & $28 \uparrow$ & 13 \\
\hline Creatinine (mg/dL) & 1.3 & 0.9 & 1.2 & 1.3 & 1.2 & 1.1 & 0.9 \\
\hline eGFR (U/L) & 40.85 & $\geq 60$ & 44.72 & $\geq 60$ & $\geq 60$ & $\geq 60$ & $\geq 60$ \\
\hline Aspartate aminotransferase $(\mathrm{U} / \mathrm{L})$ & 16 & 28 & NA & NA & 27 & NA & $42 \uparrow$ \\
\hline Alanine aminotransferase (U/L) & 18 & 30 & NA & NA & 30 & NA & 31 \\
\hline Alkaline phosphatase $(\mathrm{U} / \mathrm{L})$ & $336 \uparrow$ & 226 & NA & NA & 253 & NA & 177 \\
\hline Lactate dehydrogenase (U/L) & 382 & $1048 \uparrow$ & $1237 \uparrow$ & NA & $952 \uparrow$ & NA & $821 \uparrow$ \\
\hline Creatine phosphokinase (U/L) & 64 & 168 & $296 \uparrow$ & $1788 \uparrow$ & $271 \uparrow$ & 193 & NA \\
\hline Creatine phosphokinase-MB (U/L) & 21 & $39 \uparrow$ & NA & $54 \uparrow$ & $103 \uparrow$ & $135 \uparrow$ & NA \\
\hline $\mathrm{Ca}(\mathrm{mg} / \mathrm{dL})$ & 9.2 & $8.2 \downarrow$ & NA & NA & 9 & NA & $8.5 \downarrow$ \\
\hline Phosphorus (mg/dL) & 4.4 & $2.0 \downarrow$ & NA & NA & 3 & NA & 3.1 \\
\hline $\mathrm{Na}(\mathrm{mEq} / \mathrm{L})$ & 137 & 135 & $131 \downarrow$ & $134 \downarrow$ & $130 \downarrow$ & $130 \downarrow$ & $134 \downarrow$ \\
\hline $\mathrm{K}(\mathrm{mEq} / \mathrm{L})$ & 4.2 & 3.7 & 3.7 & 4.7 & 4.3 & 5 & 4 \\
\hline C-reactive protein (mg/L) & 3 & Negative & Negative & Negative & Negative & Negative & 1 \\
\hline Arterial blood gas & & & & & & & \\
\hline $\mathrm{PH}$ & NA & NA & 7.361 & 7.36 & NA & NA & NA \\
\hline $\mathrm{PcO}_{2}(\mathrm{mmHg})$ & NA & NA & 32.5 & 44 & NA & NA & NA \\
\hline $\mathrm{PO}_{2}(\mathrm{mmHg})$ & NA & NA & 50.2 & 20.4 & NA & NA & NA \\
\hline $\mathrm{HcO}_{3}(\mathrm{mEq} / \mathrm{L})$ & NA & NA & 18 & 24.3 & NA & NA & NA \\
\hline $\mathrm{O}_{2}$ Sat $(\%) ;($ normal range $95-100)$ & NA & NA & $82.8 \downarrow$ & $29.9 \downarrow$ & NA & NA & NA \\
\hline $\mathrm{BE}^{2}(\mathrm{mmol} / \mathrm{L})$ & NA & NA & $-6.2 \downarrow$ & -1.2 & NA & NA & NA \\
\hline $\mathrm{BB}(\mathrm{mmol} / \mathrm{L})$ & NA & NA & $41.7^{\circ}$ & 46.7 & NA & NA & NA \\
\hline
\end{tabular}

BUN: Blood urea nitrogen, eGFR: Estimated glomerular filtration rate, $\mathrm{BE}$ : Base excess, $\mathrm{BB}$ : Buffer base.

approximately $69-92 \%$ in serum LDH level in patients with COVID 19 patients, which was consistent with our findings [2], [22]. But unlike to our study, in the Xu et al. study, LDH levels increased in $27 \%$ of patients [17].

According to the results of our study, the results of chest radiography and CT scan, in most patients showed bilateral pneumonia that was consistent with the results of studies by Liu et al., Chen et al., and Chang et al. [1], [26], [27]. In another study, almost all patients had bilateral pneumonia [3], which may be attributed to the deterioration of their patients' conditions.

In our study, supportive treatments such as oxygen therapy, antibiotics, and antivirals medications were used for all patients. Antibiotic and antiviral 
medications such as ceftriaxone, meropenem, vancomycin, oseltamivir, and hydroxychloroquine were used for patients, if needed. The previous studies have also used these drugs [1], [26] However, it has been shown that despite using these medications, they were effective only in the treatment of SARS-CoV and MERS$\mathrm{CoV}$ [28] and reported that there is no strong evidence for the effective drug treatment of COVID19 [26]. However, the majority of our patients received these medications with a positive response.

\section{Conclusion}

Patients with COVID-19 associated pneumonia can be treated by evaluating and implementing appropriate therapeutic management. However, at the moment the disease progression for patients with COVID-19 cannot be accurately predicted. Prompt diagnosis, effective treatment, and use of chest CT-scan are essential for appropriate management and surveillance for disease features.

\section{Acknowledgments}

We would like to thank and appreciate the patients, nurses, physicians, and other medical staff of Razi Hospital who cared for and helped us in this study.

\section{References}

1. Chen N, Zhou M, Dong X, Qu J, Gong F, Han $Y$, et al. Epidemiological and clinical characteristics of 99 cases of 2019 novel coronavirus pneumonia in Wuhan, China: A descriptive study. Lancet. 2020;395:507-13. https://doi.org/10.1016/ S0140-6736(20)30211-7

PMid:32007143

2. Huang $\mathrm{C}$, Wang $\mathrm{Y}$, Li X, Ren L, Zhao J, Hu Y, et al. Clinical features of patients infected with 2019 novel coronavirus in Wuhan, China. Lancet. 2020;395(10223):497-506. https://doi. org/10.1016/S0140-6736(20)30183-5 PMid:31986264

3. Fu L, Wang B, Yuan T, Chen X, Ao Y, Fitzpatrick T, et al. Clinical characteristics of coronavirus disease 2019 (COVID$19)$ in China: A systematic review and meta-analysis. J Infect 2020;80(6):656-65. https://doi.org/10.1016/j.jinf.2020.03.041 PMid: 32283155

4. Bai Y, Yao L, Wei T, Tian F, Jin DY, Chen L, et al. Presumed asymptomatic carrier transmission of COVID-19. JAMA. 2020;323(14):1406-7. https://doi.org/10.1001/jama.2020.2565 PMid:32083643.

5. Singhal T. A review of coronavirus disease-2019 (COVID-19).
Indian J Pediatr 2020;87(4):281-6.

PMid: 32166607

6. Wu YC, Chen CS, Chan YJ. The outbreak of COVID-19: An overview. J Chin Med Assoc 2020;83(3):217-20. https://doi. org/10.1097/JCMA.0000000000000270

PMid: 3213486

7. Coronavirus disease 2019 (COVID-19) Situation Report 57. Available from: https://www.who.int/docs/default-source/ coronaviruse/situation-reports/20200317-sitrep-57-covid-19. pdf?sfvrsn=a26922f2_4. [Last accessed on 2020 May 30].

8. Abdi M. Coronavirus disease 2019 (COVID-19) outbreak in Iran: Actions and problems. Infect Control Hosp Epidemiol. 2020;41(6):754-5. https://doi.org/10.1017/ice.2020.86 PMid:32192541

9. Huang X, Wei F, Hu L, Wen L, Chen K. Epidemiology and clinical characteristics of COVID-19. Arch Iran Med 2020;23(4):268-71. https://doi.org/10.34172/aim.2020.09

PMid: 32271601

10. Chung $M$, Bernheim A, Mei $X$, Zhang $N$, Huang $M$, Zeng $X$ et al. CT imaging features of 2019 novel coronavirus (2019nCoV). Radiology. 2020;295(1):202-7. http://dx.doi.org/10.1148/ radiol.2020200230

PMid:32017661

11. Kolifarhood G, Aghaali M, Saadati HM, Taherpour N, Rahimi S, Izadi N, et al. Epidemiological and clinical aspects of COVID-19; a narrative review. Arch Acad Emerg Med 2020;8(1):e41. PMid: 32259130

12. Carlos WG, Dela Cruz CS, Cao B, Pasnick S, Jamil S. Nove Wuhan (2019-nCoV) Coronavirus. Am J Respir Crit Care Med. 2020;201(4):P7-8. http://dx.doi.org/10.1164/rccm.2014P7 PMid:32004066

13. Mahdavi A, Khalili N, Davarpanah AH, Faghihi T, Mahdavi A, Haseli S, et al. Radiologic management of COVID-19: Preliminary experience of the Iranian society of radiology COVID-19 consultant group (ISRCC). Iran J Radiol. 2020;17(2):e102324. https://doi.org/10.5812/iranjradiol.102324

14. Cherry J, Krogstad P. SARS: The $1^{\text {st }}$ pandemic of the $21^{\text {st }}$ Century. Pediatr Res. 2004;56(1):1-5. https://doi.org/10.1203/01. PDR.0000129184.87042.FC

PMid:15152053

15. Azhar El, El-Kafrawy SA, Farraj SA, Hassan AM, Al-Saeed MS Hashem AM, et al. Evidence for camel-to-human transmission of MERS coronavirus. N Engl J Med. 2014;370(26):2499-505. https://doi.org/10.1056/NEJMoa1401505

PMid:24896817

16. Yin Y, Wunderink RG. MERS, SARS and other coronaviruses as causes of pneumonia. Respirology. 2018;23(2):130-7. https:// doi.org/10.1111/resp.13196

PMid:29052924

17. $\mathrm{Xu} X \mathrm{XW}, \mathrm{Wu} \mathrm{XX}$, Jiang $\mathrm{XG}$, $\mathrm{Xu} \mathrm{KJ}$, Ying $\mathrm{LJ}, \mathrm{Ma} \mathrm{CL}$, et al Clinical findings in a group of patients infected with the 2019 novel coronavirus (SARS-Cov-2) outside of Wuhan, China: Retrospective case series. BMJ. 2020;368:m606. https://doi. org/10.1136/bmj.m606

PMid:32075786

18. Badawi A, Ryoo SG. Prevalence of comor twice dailyities in the Middle East respiratory syndrome coronavirus (MERS(oV): A systematic review and meta-analysis. Int J Infect Dis. 2016;49:129-33. https://doi.org/10.1016/j.ijid.2016.06.015 PMid:27352628.

19. Channappanavar R, Fett C, Mack M, Ten Eyck PP, Meyerholz DK Perlman S. Sex-based differences in susceptibility to severe acute respiratory syndrome coronavirus infection. J Immunol. 2017;198(10):4046-53. https://doi.org/10.4049/ 
jimmunol.1601896

PMid:28373583

20. Wang $X$, Yuan J, Zheng $Y$, Chen J, Bao Y, Wang $Y$, et al. Clinical and epidemiological characteristics of 34 children with 2019 novel coronavirus infection in Shenzhen. Zhonghua Er Ke Za Zhi. 2020;58:E008. https://doi.org/10.3760/ cma.j.issn.0578-1310.2020.0008

PMid:32062875

21. Wang $L$. C-reactive protein levels in the early stage of COVID-19. Med Mal Infect 2020;50(4):332-4. https://doi.org/10.1016/j. medmal.2020.03.007

PMid: 32243911

22. Chen L, Liu H, Liu W, Liu J, Liu K, Shang J,et al. Analysis of clinical features of 29 patients with 2019 novel coronavirus pneumonia. Zhonghua Jie He He Hu Xi Za Zhi. 2020;43:E005. https://doi.org/10.3760/cma.j.issn.1001-0939.2020.0005 PMid:32026671

23. Chen H, Guo J, Wang C, Luo F, Yu X, Zhang W, et al. Clinical characteristics and intrauterine vertical transmission potential of COVID-19 infection in nine pregnant women: A retrospective review of medical records. Lancet. 2020;395(10226):809-15. https://doi.org/10.1016/S0140-6736(20)30360-3

PMid:32151335

24. Shirani K, Hajzargarbashi ST. Comparison of serum CRP,
PCT and STREM-1 in ventilator-associated pneumonia (VAP) positive and VAP negative in ICU patients. J Biochem Technol. 2009;2:133-8.

25. Zhang G, Zhang J, Wang B, Zhu X, Wang Q, Qiu S. Analysis of clinical characteristics and laboratory findings of 95 cases of 2019 novel coronavirus pneumonia in Wuhan, China: A retrospective analysis. Respir Res 2020;21(1):74. https://doi. org/10.1186/s12931-020-01338-8

PMid: 32216803

26. Liu K, Chen Y, Lin R, Han K. Clinical features of COVID-19 in elderly patients: A comparison with young and middle-aged patients. J Infect 2020;80(6):e14-8. https://doi.org/10.1016/j. jinf.2020.03.005

PMid: 32171866

27. Zhang Z, Li X, Zhang W, Shi ZL, Zheng Z, Wang T. Clinical features and treatment of 2019-nCoV pneumonia patients in Wuhan: Report of a couple cases. Virol Sin. 2020 Feb 7;1-7. https://doi.org/10.1007/s12250-020-00203-8

PMid:32034637

28. Sheahan TP, Sims AC, Leist SR, Schäfer A, Won J, Brown AJ, et al. Comparative therapeutic efficacy of remdesivir and combination lopinavir, ritonavir, and interferon beta against MERS-CoV. Nat Commun. 2020;11(1):1-14. https://doi. org/10.1038/s41467-019-13940-6

PMid:31924756 